\title{
Body self-discrepancies and women's social physique anxiety: The moderating role of the feared body.
}

Woodman, Tim; Steer, R.

\section{British Journal of Psychology}

DOI:

$10.1348 / 000712610 \times 507821$

Published: 08/03/2011

Peer reviewed version

Cyswllt i'r cyhoeddiad / Link to publication

Dyfyniad o'r fersiwn a gyhoeddwyd / Citation for published version (APA):

Woodman, T., \& Steer, R. (2011). Body self-discrepancies and women's social physique anxiety: The moderating role of the feared body. British Journal of Psychology, 102(2), 147-160. https://doi.org/10.1348/000712610X507821

\section{Hawliau Cyffredinol / General rights}

Copyright and moral rights for the publications made accessible in the public portal are retained by the authors and/or other copyright owners and it is a condition of accessing publications that users recognise and abide by the legal requirements associated with these rights.

- Users may download and print one copy of any publication from the public portal for the purpose of private study or research

- You may not further distribute the material or use it for any profit-making activity or commercial gain

- You may freely distribute the URL identifying the publication in the public portal?

Take down policy

This is the peer reviewed version of the following article: 'Body self-discrepancies and women's social physique anxiety:

The moderating role of the feared body' which has been published in final form at DOI: 10.1348/000712610X507821.

This article may be used for non-commercial purposes in accordance with Wiley Terms and Conditions for SelfArchiving.

Take down policy

If you believe that this document breaches copyright please contact us providing details, and we will remove access to the work immediately and investigate your claim. 
Manuscript accepted in its current form in the British Journal of Psychology:

Woodman, T., \& Steer, R. (2011). Body self-discrepancies and women's social physique anxiety: The moderating role of the feared body. British Journal of Psychology, 102, 147-160. DOI: $10.1348 / 000712610 \times 507821$

Body self-discrepancies and women's social physique anxiety: The moderating role of the feared body

Tim Woodman \& Rebecca Steer

Bangor University, UK 


\begin{abstract}
We explored ideal, ought, and feared body image self-discrepancies as predictors of social physique anxiety within Carver, Lawrence and Scheier's (1999) and Woodman and Hemmings's (2008) interaction frameworks. One hundred women completed actual, ideal, ought, and feared body self-discrepancy visual analogue scales, the Social Physique Anxiety Scale and the Beck Depression Inventory-II. Moderated hierarchical regression analyses indicated that the relationship between ought body fat discrepancies and social physique anxiety was moderated by proximity to the feared fat self. Specifically, the positive relationship between ought fat discrepancies and social physique anxiety was stronger when women were far from their feared body self. The results highlight the importance of considering the feared self in order to more fully understand the relationship between body image and social physique anxiety.
\end{abstract}

Keywords: ideal self; ought self; feared self; body image; social physique anxiety. 
Body self-discrepancies and women's social physique anxiety: The moderating role of the feared body

Social physique anxiety - the "anxiety that people experience in response to others' evaluations of their physiques" (Hart, Leary, \& Rejeski, 1989, p. 94) - has been shown to be associated with: less exercise frequency and adherence (Lantz, Hardy, \& Ainsworth, 1997; Treasure, Lox, \& Lawton, 1998); body dissatisfaction (Krane, Waldron, Stiles-Shipley, \& Michalenok, 2001); depression and low self-esteem, (Diehl, Johnson, Rogers, \& Petrie, 1998); and anorexic and bulimic eating attitudes and behaviours such as dieting, drive for thinness and perfectionism (Crocker et al., 2003; Diehl et al., 1998; Frederick \& Morrison, 1998; Haase \& Prapavessis, 1998, 2001; Haase, Prapavessis, \& Owens, 2002; Reel \& Gill, 1996).

As social physique anxiety appears to play a crucial role in a number of health-related cognitions and behaviours it is important to understand the factors that contribute to its development. Much of the research on social physique anxiety has been conducted with the view that the further one is from one's ideal body the greater one's social physique anxiety. This body image research typically asks participants to report their 'actual' body self (e.g., actual weight and clothes size) and their 'ideal' body self (e.g., weight and clothes size they would choose if they could be any weight and size they wanted; Anton, Perri, \& Riley, 2000). The discrepancy between the actual self and the ideal self, referred to as the ideal discrepancy, has been shown to be related to a number of body-related difficulties (Anton et al., 2000; Halliwell \& Dittmar, 2006; Harrison, 2001; Forston \& Stanton, 1992; Landa \& Bybee, 2007; Snyder, 1997; Strauman, Vookles, Berenstein, Chaiken, \& Higgins, 1991) including social physique anxiety (Russell \& Cox, 2003; Sabiston, Crocker, \& Munroe-Chandler, 2005). 
Higgins's (1987) self-discrepancy theory provides a fruitful framework for examining the relationship between body image discrepancies and social physique anxiety, as it provides specific predictions for how different self-discrepancies will result in distinct types of affect. For example, Higgins proposed that the ideal self is defined by one's hopes and aspirations, and that congruence between the actual and the ideal self results in the presence of positive outcomes such as praise and reward. Discrepancy between the actual self and the ideal self (henceforth referred to as ideal discrepancies) results in the absence of positive outcomes and dejectionrelated affect such as depression. In addition to the actual and ideal selves, Higgins (1987) proposed that individuals possess an ought self: the person or qualities that an individual believes he/she should be or should possess. According to self-discrepancy theory, the ought self is defined by feelings of duty, obligation, and responsibility, and congruence between the actual and the ought self results in the absence of negative outcomes such as punishment. Discrepancy between these selves (henceforth referred to as ought discrepancies) results in the presence of negative outcomes and agitation-related affect such as anxiety.

Using global self-discrepancies, Higgins and his colleagues have conducted a number of studies that provide support for these affect-specific proposals (e.g., Higgins, 1987, 1997, 1999; Higgins, Klein, \& Strauman, 1985). However, there is evidence to indicate that the picture is not quite as clear as Higgins's (1987) theory suggests. For example, both ideal and ought discrepancies have been shown to predict both anxiety and dejection (McDaniel \& Grice, 2008; Ozgul, Huebeck, Ward, \& Wilkinson, 2003); both ideal and ought discrepancies have been shown to predict dejection with neither discrepancy predicting anxiety (Tangney, Niedenthal, Covert, \& Barlow, 1998); and ideal discrepancies have been shown to predict both anxiety and 
dejection while ought discrepancies predict neither (Gramzow, Sedikides, Panter, \& Insko, 2000).

Furthermore, with only a few exceptions (Forston \& Stanton, 1992; Snyder, 1997; Strauman et al., 1991), body image research has been focused exclusively on ideal body discrepancies with some evidence of a positive association between ideal discrepancies and social physique anxiety (Russell \& Cox, 2003; Sabiston et al., 2005). However, when one considers the specific predictions of Higgins's self-discrepancy framework, the theoretical position of this research appears somewhat simplistic. Specifically, it is important for body image research to consider references of self that go beyond simply the ideal, and consider the unique contributions of each self-discrepancy (e.g., ideal, ought). For example, if Higgins's theoretical position holds in the specific context of body image, ought discrepancies should be specifically related to social physique anxiety.

In addition to the ideal and ought selves specified within Higgins's theory, a number of authors (e.g., Markus \& Nurius, 1986; Ogilvie, 1987) have proposed that individuals possess an undesired or feared self: the self that one does not wish to become or is afraid of becoming. Although Higgins (1987) acknowledged the likelihood of a feared self, self-discrepancy theory makes no proposals with regard to its potential influence on anxiety, or any other type of affect. Ogilvie (1987) postulated that the feared self is more likely to be derived from personal experience, is less abstract, and may thus represent a stronger, more stable reference of self. However, the feared self has continued to be somewhat neglected in the self-concept literature. A notable exception is Carver, Lawrence, and Scheier's (1999) study, which incorporated the feared self into Higgins's (1987) framework by giving consideration to the motivational qualities of the different selves. Higgins (1997) contended that the ideal and ought selves are approach 
motivational; that is, one is motivated to approach these selves (e.g., "I want to be thinner"). Carver et al. (1999) proposed that the feared self is avoidance motivational; individuals are motivated to avoid becoming close to the feared self (e.g., "I don't want to become fat"). Furthermore, they proposed that the ought and feared selves may interact to predict agitation related-affect. Specifically, they argued that when people are close to their feared self, their primary motivation is to escape or to avoid it and other selves have little motivational impact; all that matters is getting away from the feared self. It is only as individuals gain some distance from their feared self (i.e., when avoidance motivation becomes less salient) that they can focus on approaching the ought self. In support of this prediction, Carver et al. revealed an interaction between ought and feared discrepancies in predicting anxiety. Specifically, when individuals were close to their feared selves, ought discrepancies were unrelated to anxiety. However, when individuals were further from their feared selves, ought discrepancies were significant predictors of anxiety.

Although recent self-discrepancy research has clearly demonstrated the importance of considering the interaction between approach and avoidance selves (e.g., Beattie, Hardy, \& Woodman, 2004; Carver et al., 1999; Heppen \& Ogilvie, 2003), little attention has been paid to this interplay in body image research. A recent study by Woodman and Hemmings (2008) was the first to examine body-specific discrepancies by extending Carver et al.'s framework. Based on this framework, they reported an interaction between ought and feared body fat discrepancies in predicting anxiety for women. Specifically, when women were closer to their feared fat self, ought fat discrepancies were not related to anxiety. It was only when women were far from their feared fat self that proximity to the ought fat self was a strong predictor of anxiety. Further, this interaction held when controlling for ideal body fat discrepancies. This suggests that body image 
research that neglects the role of the feared self tells only part of a complex picture. Drawing on previous research that has shown that women's body image concerns revolve almost exclusively around fat (e.g., Groesz, Levine, \& Murnen, 2002; Gruber, Pope, Borowiecki, \& Cohane, 2000; Wiseman, Gray, Mosimann, \& Ahrens, 1992), Woodman and Hemmings also revealed that the feared fat self moderated the ought fat discrepancy - anxiety for women but not for men. Although Woodman and Hemmings's (2008) findings are encouraging in predicting global anxiety, there still exists no evidence that such a framework is useful for predicting social physique anxiety. In fact, to the best of our knowledge, the social physique anxiety literature is devoid of any studies that consider the feared self, let alone the body image interactive framework presented by Woodman and Hemmings.

In summary, there is a paucity of research investigating the interaction between approach and avoidance body selves and their relationship with social physique anxiety and we aim to bridge this gap here. The aim of the present study was to examine ought and feared body fat discrepancies as predictors of social physique anxiety in women within Woodman and Hemmings's (2008) framework. We hypothesised a two-way interaction between ought and feared discrepancies in predicting social physique anxiety, such that the relationship between ought fat discrepancies and social physique anxiety would be moderated by feared fat discrepancies. Specifically, we expected ought discrepancies to be positively related to social physique anxiety only when women are far from their feared self; when they are close to their feared body, ought discrepancies should be relatively unrelated to social physique anxiety. Finally, in line with Higgins's (1987) proposals, we expected this pattern of results to hold when controlling for the ideal self. 


\section{Participants}

One hundred women $\left(M_{\mathrm{age}}=30.10\right.$ years, $\left.S D=11.14\right)$ were recruited via opportunistic community-based sampling. The sample was primarily Caucasian, consisting of undergraduate and postgraduate students, and members of the general population. The mean body mass index (BMI; weight $(\mathrm{kg})$ divided by height squared $\left.\left(\mathrm{m}^{2}\right)\right)$ of the sample was $26.17(S D=4.53)$. The study was approved by the institutional ethics board and written informed consent was obtained from all participants.

\section{Measures}

Demographic questionnaire. Participants completed a brief demographic questionnaire providing information about their age, height and weight. Previous research has indicated that social physique anxiety is positively associated with BMI (e.g., Crawford \& Eklund, 1994; Eklund \& Crawford, 1994) and negatively associated with age (Treasure et al., 1998). Furthermore, ideal-related body discrepancies and body dissatisfaction have been shown to decline with age (Landa \& Bybee, 2007). Thus, height and weight (to calculate BMI) and age data were obtained so that they could be controlled in subsequent analyses.

Body discrepancies. Using four separate $15 \mathrm{~cm}$ visual analogue scales, we asked participants to indicate (1) how fat you feel your body actually is (actual self), (2) how fat you feel your body ought to be (ought self), (3) how fat you ideally would like your body to be (ideal self), and (4) how fat you fear your body being (feared self). The visual analogue scales ranged from 0 (not at all fat) to 15 (extremely fat). Body discrepancies were calculated by creating an absolute difference score between the actual score and the ought, ideal, and feared scores.

Assumptions underlying discrepancy scores. According to Edwards (1994), discrepancy

scores are appropriate to use only when the individual components exert opposite but equal 
effects on the dependent variable. To examine whether our data met these criteria, we conducted two-step regression analyses for the actual self compared to the ought, and feared selves on social physique anxiety. The magnitude of the effect of the actual self $\left(\beta_{\text {actual }}=.54, p<.001\right)$ and the ought self $\left(\beta_{\text {ought }}=-.28, p<.005\right)$ was opposite in sign and not significantly different $(t(100)$ $=2.51, \mathrm{~ns})$. However, the effects of the actual self $\left(\beta_{\text {actual }}=.40, p<.001\right)$ and the feared self $\left(\beta_{\text {feared }}=.12, \mathrm{~ns}\right)$ were not in the opposite direction. In purely statistical terms, this suggests that the discrepancy scores for the ought self are sound and the discrepancy scores for the feared self are suspect (see Edwards, 1994). However, we retained the feared and ought discrepancies on conceptual grounds. That is, one would expect the actual self and the ought self to reveal opposite and approximately equal effects on social physique anxiety. Conversely, one would expect the actual self and the feared self to reveal effects on social physique anxiety that are in the same direction (i.e., the fatter I feel, the more anxious I feel; the fatter I fear becoming, the more anxious I feel). This argument notwithstanding, the similarity of the actual and feared effects yields a concern about the actual self pre-empting any feared self effects. Thus, to allay any such concerns, we controlled for the actual self component throughout the analyses. It is worth noting that these difference score assumptions are typically not tested in self-discrepancy theory research, which is rather surprising given that difference scores are a central tenet of the theory and its derivatives ${ }^{1}$.

Social Physique Anxiety. The nine-item Social Physique Anxiety Scale (SPAS; Martin, Rejeski, Leary, McAuley, \& Bane, 1997) is a single-factor self-report scale that assesses the degree of anxiety that individuals feel when they perceive others to be evaluating their physique. It includes items such as "It would make me uncomfortable to know others were evaluating my physique/figure.' Responses are scored on a five-point Likert scale ranging from 1 (not at all 
characteristic) to 5 (extremely characteristic). A mean social physique anxiety score is then calculated. The nine-item SPAS has demonstrated good internal consistency in both men $(\alpha=$ $.84)$ and women $(\alpha=.87$; Strong, Martin-Ginis, Mack, $\&$ Wilson, 2006). In the current sample the Cronbach's alpha coefficient was .90 .

Depression. The Beck Depression Inventory-II (BDI-II; Beck, Steer, \& Brown, 1996) is a single-factor, 21-item measure of depression. Each item contains four statements that are rated on a scale of increasing severity of depression from 0 to 3 (e.g., $0=$ I do not feel sad; $3=$ I am so sad or unhappy that I can't stand it). The measure asks participants to select one statement from each of the 21 items that most closely matches their feelings over the previous two weeks. The scores from the 21 items are summed to give a total depression score between 0 and 63 . The BDI-II has good internal consistency in both clinical $(\alpha=.92)$ and non-clinical samples $(\alpha=.93$; Beck et al., 1996). In the current sample the Cronbach's alpha coefficient was .88. This measure was administered with a view to controlling for depression in the analyses (cf. Diehl et al., 1998).

\section{Procedure}

We told participants that the study was an investigation of body image. After completing the informed consent form and the demographic questionnaire, participants were provided with definitions of each of the body selves (actual, ought, ideal, and feared) as follows:

Actual self: Your Actual body fatness refers to how fat you feel you actually are at this point in time.

Ought Self: Your Ought body fatness refers to how fat you feel obliged to be, either by personal or outside pressures.

Ideal Self: Your Ideal body fatness refers to how fat you would ideally like to be.

Feared Self: Your Feared body fatness refers to how fat you fear or worry about being. 
Participants then completed the measure of body discrepancies, the Social Physique Anxiety Scale, and the Beck Depression Inventory-II. Confidentiality was assured throughout. Data analysis

Descriptive statistics and zero-order correlations are presented in Table 1. Moderated hierarchical regression analyses were conducted to examine the two-way interaction hypotheses. Multicollinearity was checked throughout; Menard (1995) suggests that tolerance statistics of below 0.2 are of concern. Multicollinearity was not of concern in the present data as the lowest tolerance statistic was .28, with the majority above .9 .

In line with previous research (Gramzow et al., 2000; Ozgul et al., 2003; Tangney et al., 1998; Woodman \& Hemmings, 2008), descriptive statistics indicated a significant relationship between ideal and ought fat discrepancies $(r=.86, p<.001)$. Descriptive statistics also indicated a significant relationship between social physique anxiety and depression $(r=.47, p<.001)$; and between social physique anxiety and age $(r=-.28, p<.01)$. Subsequently, in the analyses we controlled for the ideal and actual body image components, depression, and age. Although descriptive statistics revealed no significant relationship between BMI and social physique anxiety $(r=.14$, ns $)$, we chose to control for BMI also to ensure that any subjective body image effects were significant over and above relatively objective body physique data.

Results

Ought self-discrepancies and social physique anxiety

Based on the work of Carver et al. (1999) and Woodman and Hemmings (2008), we sought to examine the hypothesis that the relationship between ought body discrepancies and social physique anxiety would be moderated by feared discrepancies. We entered the variables for the moderated hierarchical regression analysis in the following order: (1) Control variables: 
actual self, ideal self, depression, age, and BMI; (2) Ought and feared discrepancy; (3) Ought x feared discrepancy.

As indicated in Table 2, when controlling for the actual body component $(\beta=.37, p<$ $.05)$, the ideal body component $(\beta=-.23, p<.05)$, depression $(\beta=.29, p<.001)$, age $(\beta=-.27, p$ $<.001)$, and BMI $(\beta=-.07, \mathrm{~ns})$, the two-way interaction accounted for a significant proportion of social physique anxiety variance over and above the main effects, $R_{\text {cha }}^{2}=.07, p<.001 ; \beta=.33, p$ $<.001$. The two-way interaction is depicted in Figure 1. Simple slopes analyses indicated that the positive relationship between ought fat discrepancies and social physique anxiety was stronger when women were far from their feared self $(\beta=.92, p<.001)$ than when they were close to their feared self $(\beta=.31, p<.005)$.

Distinction between ought and ideal fat selves.

The similitude of results for ought and ideal fat selves in predicting social physique anxiety (see Table 1) calls to question the conceptual distinction between them. Thus, $t$-tests were conducted to examine if individuals' self-report ought and ideal fat selves were meaningfully distinct. Results indicated the ought fat selves were rated significantly higher (fatter) than ideal fat selves $\left(M_{\text {ought }}=3.34, S D=2.40 ; M_{\text {ideal }}=2.86, S D=1.87 ; t(99)=2.64, p<\right.$ .01), which suggests that women hold distinct ought and ideal selves.

\section{Directional discrepancies}

A traditional self-discrepancy theory approach to body image discrepancies has been adopted throughout the previous analyses by using absolute discrepancy scores. That is, in line with previous research (e.g., Woodman \& Hemmings, 2008), we conceptualised positive and negative discrepancies as non-directional discrepancies. As Woodman and Hemmings (2008) pointed out, in adopting such a stance, one does not allow for the emergence of the potential 
moderating effect of discrepancy direction on the discrepancy-affect relationship. In the current sample, positive ought discrepancies (i.e., ought to be more fat) were reported by 10 women. Positive ideal discrepancies (i.e., ideally want to be more fat) were reported by one woman. Finally, eight women reported negative feared discrepancies (i.e., fear being less fat). To ensure that these data were not unduly affecting the analyses, we re-ran the regression analyses after their removal. The analysis revealed that after removal of these data and controlling for the actual body component $(\beta=.57, p<.005)$, the ideal body component $(\beta=-.32, p<.01)$, depression $(\beta=.33, p<.001)$, age $(\beta=-.23, p<.005)$, and BMI $(\beta=-.00, \mathrm{~ns})$, the two-way interaction continued to significantly predict social physique anxiety over and above the main effects, $R_{\text {cha }}^{2}=.06, p<.001 ; \beta=.29, p<.001$. Simple slopes analysis indicated that the positive relationship between the ought self and social physique anxiety was stronger when women were far from their feared self $(\beta=.86, p<.001)$ than when they were close to their feared self $(\beta=$ $.44, p<.001)$

\section{Discussion}

The data from the present study confirm and extend Carver et al.'s (1999) and Woodman and Hemmings's (2008) anxiety interaction framework. As hypothesised, the two-way interaction between ought and feared body fat discrepancies was significant in predicting social physique anxiety. Specifically, ought fat discrepancies were more strongly associated with social physique anxiety when women were far from their feared fat self compared to when they were near their feared self. These findings provide initial evidence that social physique anxiety is better predicted by a combination of approach and avoidance body self-guides than by individual self guides alone. 
The similitude of the simple effects of the ideal and ought selves on social physique anxiety is in contrast to Higgins's (1987) contention that ought discrepancies uniquely predict agitation-related affect, and initially appears to call into question the distinction between these two selves in the context of body image. Groesz et al. (2002) suggested that external standards for body shape and size are portrayed so prolifically by the media in Western societies that they may largely have been internalized as one's own ideals. In other words, the distinction between oughts and ideals may have become rather blurred when it comes to body image. As such, women may feel driven to achieve these standards not only to avoid negative consequences such as negative social evaluation and prejudice but also to fulfil their now internalized aspirations of thinness to avoid negative self-evaluations. However, in the present study, women reported significantly distinct ideal and ought selves, suggesting that the similitude of relationships between the self-guides and social physique anxiety cannot be attributed to a lack of distinction between these two approach selves. Thus, as both ideal and ought selves were conceptually and empirically distinct, they deserve to be investigated in an orthogonal manner in future research. This theoretical and empirical distinction between ought and ideal selves is further supported by research on eating disorders, which has found ideal discrepancies to be associated with bulimicrelated behaviours and ought discrepancies to be associated with anorexic-related behaviours (Strauman et al., 1991).

The significant interactions between the approach self (i.e., the ought self) and the avoidance self (i.e., the feared self) highlights that body image literature that examines exclusively the approach self (i.e., the ideal or ought self) is neglecting an important element of body image: the relationship between the feared self and social physique anxiety. In line with previous research (Beattie et al., 2004; Carver et al., 1999; Heppen \& Ogilive, 2003; Woodman 
\& Hemmings, 2008), the present findings suggest that approach body self guides are relatively weak predictors of social physique anxiety when close to the feared body fat self. However, as individuals achieve some distance from their feared fat self the focus shifts to approaching a desired self, which subsequently emerges as the stronger predictor of social physique anxiety (see also Russell \& Cox, 2003; Sabiston et al., 2005).

In conjunction with previous research (e.g., Woodman \& Hemmings, 2008), these results have important implications both for future body image research and for practitioners dealing with social physique anxiety. For example, a practitioner may attempt to help modify unrealistic and often unattainable personal ideals to more realistic, attainable levels. However, the framework outlined and supported in the present study suggests that a one-dimensional focus on such an approach ideal may be relatively fruitless. That is, if the person feels close to the feared self (i.e., "I feel fat") then the most important focus should be on gaining some distance from this proximal feared self. This is because the proximity to feared self may lead to feelings of helplessness ("whatever the distance from the ideal, I feel relatively anxious"). The focus on first gaining distance from the feared self is especially important in the context of social physique anxiety given its potential subsequent impact on eating and exercise behaviours (e.g., Diehl et al., 1998; Haase et al., 2002). For example, people may be more motivated to eat healthily and to exercise only once they have achieved some distance from their feared self. This appears a particularly worthy avenue for future research.

The present study has made a number of advances from Woodman \& Hemmings's (2008) study. First, whereas Woodman and Hemmings's focus was on global anxiety, we refined this approach to target body-specific anxiety (i.e., social physique anxiety). This ensured that the body discrepancies were indeed related to a theorised body-specific anxiety. Second, to derive 
body discrepancies, Woodman and Hemmings used the somatomorphic matrix (Gruber et al., 2000), which is an interactive computer program through which individuals are asked to navigate through a 10x10 matrix of 100 images based on reference photographs of individuals at known body fat and muscularity percentages and select the images that most closely resemble their actual and ideal selves. We chose instead to use visual analogue scales to derive body discrepancies. Such scales have the advantage of allowing individuals to imprint their own subjective view onto the scale rather than having unrealistic images of body shapes imposed upon them. Using this more subjective measure the present data revealed similar findings to Woodman and Hemmings, thus strengthening their findings and providing support for the use of their framework to examine body fat discrepancies. However, the use of a single-item scale via either a somatomorphic matrix or a visual analogue rather than via a multi-item measure of body self discrepancies presents its own limitations. Given this limitation and that body image is an inherently subjective experience, we believe future research would do well to utilise a multi-item measure that encourages participants to embrace this subjectivity. For example, a modified version of the Selves questionnaire (Higgins et al., 1985) specifically directed at body image and incorporating the feared self would allow participants subjectively to identify the aspects of body image relevant to them.

Self-discrepancy theory does not make any specific predictions about the direction of discrepancies. In other words, it is the distance that counts regardless of the direction of such distance. In the context of body image, although a large proportion of individuals report discrepancies in the expected direction (i.e., wanting to be less fat), discrepancies may be bidirectional (e.g., one may desire to be fatter). Woodman and Hemmings (2008) contended that using directional discrepancy scores may be problematic, as they imply that negative 
discrepancies will result in weaker affect than zero discrepancies. The obvious way around this problem is to use absolute discrepancy scores, which we did here. Using absolute discrepancy scores is not without its problems also. This is because the type and intensity of affect experienced by an individual who desires to be less fat may be different to that experienced by an individual who desires to be fatter. However, when we removed those discrepancies that were not in the direction of the majority of participants (i.e., I ought to be fatter), the results of the analyses remained unchanged. Despite these findings, direction should not be abandoned as a potential research avenue. For example, research with samples that espouse different cultural body image ideals may yield meaningful direction effects.

Despite attempts to address methodological limitations from previous research, the present study has limitations of its own. For example, whereas Higgins's (1987) theory proposes that self discrepancies are the cause of affective states, the cross-sectional design of the present study does not allow one to test for such causation. Although the present findings add further correlational support to the growing amount of research examining a self-discrepancy interaction framework (Beattie et al., 2004; Carver et al., 1999; Heppen \& Ogilvie, 2003; Woodman \& Hemmings, 2008), future research should begin to examine the robustness of this interaction framework in experimental designs (e.g., through manipulation of self-discrepancies via exposure to ideal and/or feared media images).

In summary, the present results support those of previous self-discrepancy research (Carver et al., 1999; Woodman \& Hemmings, 2008) and provide evidence for the robustness of this interaction framework in predicting social physique anxiety. This study is the first to demonstrate that the feared body self moderates the relationship between the ought body self and social physique anxiety. The approach body self of the ought body impacted social physique 
anxiety more strongly when sufficient distance was gained from the feared body self. Body image research would do well to consider this interplay between approach and avoidance selves in future research. Further, we recommend that such research examine in greater detail the distinction between ideal and ought selves in predicting social physique anxiety and any related behaviours including eating and exercise. 


\section{References}

Anton, S. D., Perri, M. G., \& Riley, J. R. (2000). Discrepancy between actual and ideal body images impact on eating and exercise behaviours. Eating Behaviors, 1, 153-160.

Beattie, S., Hardy, L., \& Woodman, T. (2004). Pre-competition self-confidence: the role of the self. Journal of Sport and Exercise Psychology, 26, 427-441.

Beck, A. T., Steer, R. A., \& Brown, G. K. (1996). Manual for the Beck Depression Inventory-II. San Antonio, TX: Psychological Corporation.

Carver, C. S., Lawrence, J. W., \& Scheier, M. J. (1999). Self-discrepancies and affect: Incorporating the role of feared selves. Personality and Social Psychology Bulletin, 25, 783-792.

Crawford, S., \& Eklund, R. C. (1994). Social Physique Anxiety, Reasons for Exercise, and Attitudes Toward Exercise Settings. Journal of Sport and Exercise Psychology, 16, 70-82.

Crocker, P., Sabiston, C., Forrestor, S., Kowlaski, N., Kowalski, K., \& McDonough, M. (2003). Predicting change in physical activity, dietary restraint, and physique anxiety in adolescent girls. Canadian Journal of Public Health, 94, 332-337.

Diehl, N. S., Johnson, C. E., Rogers, R. L., \& Petrie, T. A. (1998). Social physique anxiety and disordered eating: what's the connection? Addictive Behaviors, 23, 1-6.

Edwards, J. R. (1994). The study of congruence in organizational behavior research: Critique and proposed alternative. Organizational Behavior and Human Decision Processes, 58, 51-100.

Eklund, R. C., \& Crawford, S. (1994). Active women, social physique anxiety, and exercise. Journal of Sport and Exercise Psychology, 16, 431-448.

Frederick, C. M., \& Morrison, C. S. (1998). A mediational model of social physique anxiety and eating disordered behaviours. Perceptual and Motor Skills, 86, 139-145. 
Forston, M. T., \& Stanton, A. L. (1992). Self-discrepancy theory as a framework for understanding bulimic symptomatology and associated distress. Journal of Social and Clinical Psychology, 11, 103-118.

Gramzow, R. H., Sedikides, C., Panter A. T., \& Insko, C. A. (2000). Aspects of self-regulation and self structure as predictors of perceived emotional distress. Personality and Social Psychology Bulletin, 26, 188-205.

Groesz, L. M., Levine, M. P., \& Murnen, S. K. (2002). The effect of experimental presentation of thin-media images on body satisfaction: A meta-analytic review. International Journal of Eating Disorders, 31, 1-16.

Gruber, A. J., Pope, H. G., Borowiecki, J. J., \& Cohane, G. (2000). The development of the somatomorphic matrix: a biaxial instrument for measuring body image in men and women. In: Norton K, Olds T, Dollman J, editors. Kinanthropometry VI. (pp. 217-231). Adelaide, Australia, International Society for the Advancement of Kinanthropometry.

Haase, A. M, \& Prapavessis, H. (1998). Social physique anxiety and eating attitudes: moderating effects of body mass and gender. Psychology, Health and Medicine, 3, 201-210.

Haase, A. M, \& Prapavessis, H. (2001). Social physique anxiety and eating attitudes in female athletic and non-athletic groups. Journal of Science and Medicine in Sport, 4, 396-405.

Haase, A. M, \& Prapavessis, H., \& Owens, R. G. (2002). Perfectionism, social physique anxiety and disordered eating: a comparison of male and females elite athletes. Psychology of Sport and Exercise, 3, 209-222.

Halliwell, E., \& Dittmar, H. (2006). Associations between appearance related self discrepancies and young women's and men's affect, body satisfaction, and emotional eating: A comparison of fixed-item and participant-generated self-discrepancies. Personality and 
Social Psychology Bulletin, 32, 447-458.

Harrison, K. (2001). Ourselves, our bodies: Thin-ideal media, self-discrepancies, and eating disorder symptomatology in adolescents. Journal of Social and Clinical Psychology, 20, 289-323.

Hart, E. A., Leary, M. R., \& Rejeski, J. (1989). The measurement of social physique anxiety. Journal of Sport and Exercise Psychology, 11, 94-104.

Heppen, J. B., \& Ogilvie, D. M. (2003). Predicting affect from global self-discrepancies: the dual role of the undesired self. Journal of Social and Clinical Psychology, 22, 347-368.

Higgins, E. T. (1987). Self-discrepancy: A theory relating self and affect. Psychological Review, 94, 319-340.

Higgins, E. T. (1997). Beyond pleasure and pain. American Psychologist, 52, 1280-1300.

Higgins, E. T. (1999). When do self-discrepancies have specific relations to emotions? The second-generation question of Tangney, Niedenthal, Covert and Barlow (1998). Journal of Personality and Social Psychology, 77, 1313-1317.

Higgins, E. T., Klein, R., \& Strauman, T. J. (1985). Self-concept discrepancy theory: A psychological model for distinguishing among different aspects of depression and anxiety. Social Cognition, 3, 51-76.

Krane, V., Stiles-Shipley, J. A., Waldron, J., \& Michalenok, J. (2001). Relationships among body satisfaction, social physique anxiety, and eating behaviors in female athletes and exercisers. Journal of Sport Behavior, 24, 247-264.

Landa, C. E., \& Bybee, J. A. (2007). Adaptive elements of aging: Self-image discrepancy, perfectionism and eating problems. Developmental Psychology, 43, 83-93.

Lantz, C. D., Hardy, C. J., \& Ainsworth, B. E. (1997). Social physique anxiety and perceived 
exercise behavior. Journal of Sport Behavior, 20, 83-93.

Markus, H., \& Nurius, P. (1986). Possible selves. American Psychologist, 41, 954-969.

Martin, K. A., Rejeski, W. J., Leary, M. R., McAuley, E., \& Bane, S. (1997). Is the social physique anxiety scale really multidimensional? Conceptual and statistical arguments for a unidimensional model, Journal of Sport and Exercise Psychology, 19, 359-367.

McDaniel, B. L. \& Grice, J. W. (2008). Predicting psychological well-being from selfdiscrepancies: A comparison of idiographic and nomothetic measures. Self and Identity, 7, 243-261.

Menard, S. (1995). Applied logistic regression analysis. Sage university paper series on quantitative applications in the social sciences, no. 07 - 106. Thousand Oaks, CA: Sage.

Ogilive, D. M. (1987). The undesired self: A neglected variable in personality research. Journal of Personality and Social Psychology, 52, 379-385.

Ozgul, S., Huebeck, B., Ward, J., \& Wilkinson, R. (2003). Self-discrepancies: measurement and relation to various negative affective states. Australian Journal of Psychology, 55, 56-62.

Reel, J. J., \& Gill, D. L. (1996). Psychosocial factors related to eating disorders among high school and college female cheerleaders. The Sport Psychologist, 10, 195-206.

Russell, W. D., \& Cox, R. H. (2003). Social physique anxiety, body dissatisfaction, and selfesteem in college females of differing exercise frequency, perceived weight discrepancy, and race. Journal of Sport Behavior, 26, 298-319.

Sabiston, C. M., Crocker, P. R. E., \& Munroe-Chandler, K. J. (2005). Examining current-ideal discrepancy scores and exercise motivations as predictors of social physique anxiety in exercising women. Journal of Sport Behavior, 28, 68-85.

Snyder, R. (1997). Self-discrepancy theory, standards for body evaluation, and eating disorder 
symptomatology among college women. Women and Health, 26, 69-84.

Strauman, T. J., Vookles, J., Berenstein, V., Chaiken, S., \& Higgins, E. T. (1991). Selfdiscrepancies and vulnerability to body dissatisfaction and disordered eating. Journal of Personality and Social Psychology, 61, 946-956.

Strong, H. A., Martin-Ginis, K. A., Mack, D. E., \& Wilson, P. M. (2006). Examining selfpresentational exercise motives and social physique anxiety in men and women. Journal of Applied Biobehavioral Research, 11, 209-225.

Tangney, J. P., Niedenthal, P. M., Covert, M. V., \& Barlow, D. H. (1998). Are shame and guilt related to distinct self-discrepancies? A test of Higgins's (1987) hypotheses. Journal of Personality and Social Psychology, 75, 256-268.

Treasure, D. C., Lox, C. L., Lawton, B. R. (1998). Determinants of physical activity in a sedentary obese female population. Journal of Sport and Exercise Psychology, 20, 218224.

Wiseman, C.V., Gray, J. J., Mosimann, J. E., \& Ahrens, A. H. (1992). Cultural expectations of thinness in women: An update. International Journal of Eating Disorders, 11, 85-89.

Woodman, T., \& Hemmings, S. (2008). Body image self-discrepancies and affect: Exploring the feared body self. Self and Identity, 7, 413-429. 
Body Self-discrepancies and Social Physique Anxiety 24

\section{Footnote}

1. We are grateful to an anonymous reviewer for pointing this out. 
Body Self-discrepancies \& Social Physique Anxiety 25

Table 1. Zero-order correlations and descriptive statistics.

\begin{tabular}{|c|c|c|c|c|c|c|c|c|c|c|c|}
\hline & BMI & SPA & Age & BDI & $\begin{array}{c}\text { Actual } \\
\text { Fat }\end{array}$ & Ideal Fat & $\begin{array}{l}\text { Ought } \\
\text { Fat }\end{array}$ & $\begin{array}{c}\text { Feared } \\
\text { Fat }\end{array}$ & $\begin{array}{c}\text { Ideal Fat } \\
\text { Disc }\end{array}$ & $\begin{array}{l}\text { Ought } \\
\text { Fat Disc }\end{array}$ & $\begin{array}{c}\text { Feared } \\
\text { Fat Disc }\end{array}$ \\
\hline \multicolumn{12}{|l|}{ BMI } \\
\hline SPA & .14 & & & & & & & & & & \\
\hline Age & .11 & $-.28 * *$ & & & & & & & & & \\
\hline BDI & .02 & $.47 * * *$ & -.05 & & & & & & & & \\
\hline Actual Fat & $.58 * * *$ & $.46 * * *$ & .15 & $.26^{* *}$ & & & & & & & \\
\hline Ideal Fat & $.37 * * *$ & -.10 & $.23 *$ & -.05 & $.45 * * *$ & & & & & & \\
\hline Ought Fat & $.31 * *$ & -.14 & -.04 & -.05 & $.28 * *$ & $.67 * * *$ & & & & & \\
\hline Feared Fat & $.24^{*}$ & $.31 * *$ & -.15 & $.23^{*}$ & $.46 * * *$ & .08 & .09 & & & & \\
\hline Ideal Fat Disc & $.39 * * *$ & $.58 * * *$ & .02 & $.32 * * *$ & $.80 * * *$ & -.19 & -.15 & $.45 * * *$ & & & \\
\hline Ought Fat Disc & $.31 * *$ & $.53 * * *$ & .15 & $.29 * *$ & $.72 * * *$ & -.09 & $-.43 * * *$ & $.37 * * *$ & $.86^{* * * *}$ & & \\
\hline Feared Fat Disc & $-.27 * *$ & $-.23^{*}$ & -.16 & -.09 & $-.49 * * *$ & $-.33 * * *$ & -.19 & $.43 * * *$ & $-.32 * * *$ & $-.31 * *$ & \\
\hline $\begin{array}{c}\text { Women } \\
\text { Mean (SD) }\end{array}$ & $\begin{array}{l}26.17 \\
(4.53)\end{array}$ & $\begin{array}{l}3.20 \\
(.94)\end{array}$ & $\begin{array}{c}30.10 \\
(11.14)\end{array}$ & $\begin{array}{c}9.27 \\
(7.38)\end{array}$ & $\begin{array}{c}7.27 \\
(3.05)\end{array}$ & $\begin{array}{c}2.86 \\
(1.87)\end{array}$ & $\begin{array}{c}3.34 \\
(2.40)\end{array}$ & $\begin{array}{l}10.99 \\
(3.19)\end{array}$ & $\begin{array}{c}4.41 \\
(2.77)\end{array}$ & $\begin{array}{c}4.14 \\
(3.06)\end{array}$ & $\begin{array}{l}4.03 \\
(2.85)\end{array}$ \\
\hline
\end{tabular}

${ }^{*} p<.05, * * p<.01, * * * p<.001$; Women $(\mathrm{n}=100) \mathrm{BMI}=$ body mass index; SPA = social physique anxiety; BDI = Beck depression inventory; Ideal, Ought and Feared Fat Disc $=$ Fat Discrepancies. 
Body Self-discrepancies \& Social Physique Anxiety 26

Table 2. Moderated hierarchical regression analysis for Ought body fat self-discrepancies and Feared body fat self-discrepancies on Social Physique Anxiety.

\begin{tabular}{|c|c|c|c|c|c|c|}
\hline Variables entered & $R^{2}$ & $R_{\text {cha }}^{2}$ & $F_{\text {cha }}$ & $\mathrm{df}$ & $\beta$ & $t$ \\
\hline \multicolumn{7}{|l|}{ Step 1} \\
\hline Actual body self & .50 & .50 & $18.12 * * *$ & 5,90 & .37 & $2.19 *$ \\
\hline Ideal body self & & & & & -.23 & $-2.13^{*}$ \\
\hline Depression (BDI) & & & & & .29 & $4.05^{* * *}$ \\
\hline Age & & & & & -.27 & $-3.68 * * *$ \\
\hline BMI & & & & & -.07 & -.87 \\
\hline Step 2 & .51 & .01 & 1.51 & 2,88 & & \\
\hline Ought body self-discrepancy & & & & & .30 & $2.11 *$ \\
\hline Feared body self-discrepancy & & & & & .05 & .65 \\
\hline Step 3 & .59 & .07 & $16.73 * * *$ & 1,87 & & \\
\hline Ought x Feared body self-discrepancy & & & & & .33 & $4.09 * * *$ \\
\hline
\end{tabular}

$* p<.05, * * p<.01 * * * p<.001$ 
Body Self-discrepancies \& Social Physique Anxiety 27

\section{Figure Captions}

Figure 1. The two-way interaction between ought and feared fat discrepancy on social physique anxiety. Regression slopes are derived from regression equations with hypothetical individuals who are one standard deviation below the mean (close to) or one standard deviation above the mean (far from). 


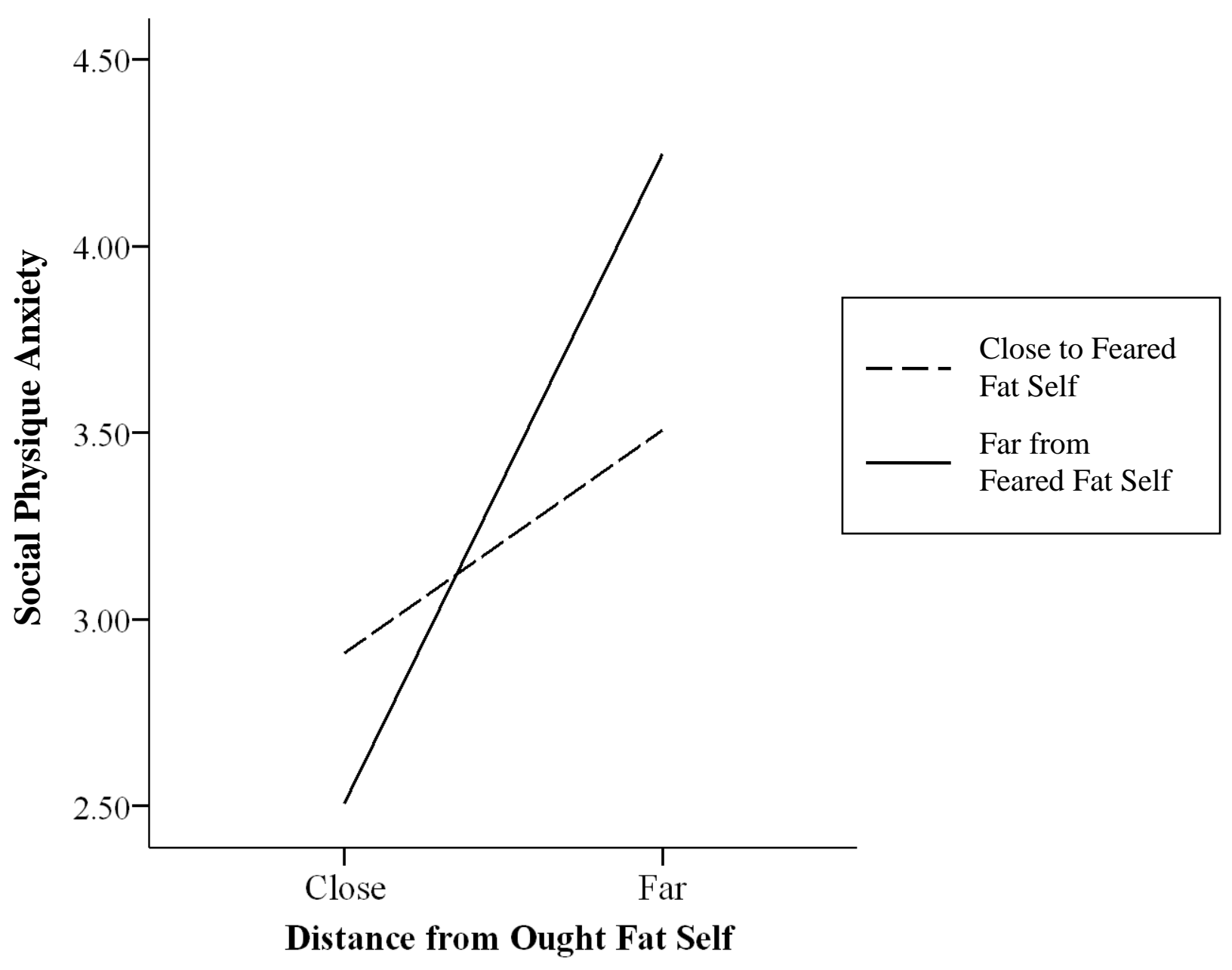

